Canadian

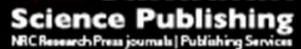

Canadian Journal of Forest Research Revue canadienne de recherche forestière

\title{
Long-term influence of stand thinning and repeated fertilization on forage production in young lodgepole pine forests
}

\begin{tabular}{|r|l|}
\hline Journal: & Canadian Journal of Forest Research \\
\hline Manuscript ID & cjfr-2016-0507.R1 \\
\hline Manuscript Type: & Article \\
\hline Date Submitted by the Author: & 24-Feb-2017 \\
\hline Keywlete List of Authors: & $\begin{array}{l}\text { Lindgren, Pontus; University of British Columbia, } \\
\text { Sullivan, Druscilla; Applied Mammal Research Institute } \\
\text { Sullivan, Thomas; University of BC, } \\
\text { Ransome, Douglas; British Columbia Institute of Technology } \\
\text { Zabek, Lisa; British Columbia Ministry of Agriculture, }\end{array}$ \\
\hline fertilization, lodgepole pine forest, silviculture, silvopasture, cattle grazing \\
\hline $\begin{array}{r}\text { Is the invited manuscript for } \\
\text { consideration in a Special } \\
\text { Issue? : }\end{array}$ & N/A \\
\hline &
\end{tabular}


1 Long-term influence of stand thinning and repeated

2 fertilization on forage production in young lodgepole pine

3 forests

4

5

6

7

8 Pontus M.F. Lindgren ${ }^{\mathrm{a}}$, Thomas P. Sullivan ${ }^{\mathrm{b}, *}$, Douglas B. Ransome ${ }^{\mathrm{a}}$, Druscilla S.

9 Sullivan $^{\mathrm{a}}$, Lisa Zabek ${ }^{\mathrm{c}}$

10

11 a Applied Mammal Research Institute, 11010 Mitchell Ave., Summerland, British

12 Columbia, Canada $\mathrm{VOH} 1 \mathrm{Z8}$

$13{ }^{\mathrm{b}}$ Department of Forest and Conservation Sciences, Faculty of Forestry, University of

14 British Columbia, 2424 Main Mall, Vancouver, BC, Canada V6T $1 Z 4$

$15{ }^{\mathrm{c}}$ Ministry of Agriculture, 441 Columbia Street, Kamloops, British Columbia, Canada

$16 \quad V 2 C 2 T 3$

17

18

19

20

$21{ }^{*}$ Corresponding author.

22 E-mail address: tom.sullivan@ubc.ca (T.P. Sullivan)

23 
24 Abstract: Integration of trees with forage and livestock production as silvopastoralism is

25 another potential component of intensive forest management. Stand thinning and

26 fertilization may enhance growth of crop trees and understory forage for livestock. We

27 tested the hypothesis that large-scale pre-commercial thinning (PCT) (particularly heavy

28 thinning to $\leq 1000$ stems/ha) and repeated fertilization, up to 20 years after the onset of

29 treatments, would enhance production of graminoids, forbs, and shrubs as cattle (Bos

30 taurus L.) forage. Results are from two long-term studies: (1) PCT (1988-2013) and (2)

31 PCT with fertilization (PCT-FERT) (1993-2013) of lodgepole pine (Pinus contorta Dougl.

32 ex Loud. var. latifolia Engelm.) stands in south-central British Columbia, Canada. Mean

33 biomass estimates of graminoids, forbs, total herbs, and shrubs were not affected by

34 stand density. However, fertilization enhanced mean biomass estimates of graminoids,

35 forbs, and total herbs, but not shrubs. Thus, the density part of our hypothesis was not

36 supported, but the nutrient addition part was supported at least for the herbaceous

37 components. Biomass of the herbaceous understory was maintained as a silvopasture

38 component for up to 20 years (stand age 13 to 33 years) in fertilized heavily thinned

39 stands, prior to canopy closure.

40

41 Keywords: cattle grazing; fertilization; herbaceous forage; lodgepole pine forest; stand

42 thinning.

43

44 


\section{Introduction}

46 The silvicultural practices of stand thinning and fertilization have been used

47 successfully to increase biomass production in temperate zone forests (Moore and Allen

48 1999; Fox et al. 2007). Another potential component of intensive forest management is

49 silvopastoralism which is an agroforestry practice that intentionally integrates trees with

50 forage and livestock production (Sharrow 1999; Clason and Sharrow 2000). Depending

51 on how and where it is applied, this form of agroforestry has the potential to be more

52 integrated and profitable than single resource management (McDonald and Fiddler

53 1993; Husak and Grado 2002). Forage productivity peaks soon after any disturbance

54 that removes tree cover or foliage (e.g., insect outbreaks, wildfire, harvesting). Cattle

55 readily forage on graminoids, forbs, and some shrub species during summer grazing in

56 these upland forest habitats (Willms et al. 1980; Holechek et al. 1982; Quinton 1984).

57 There is then a predictable decline over successional time as the tree layer regains

58 dominance and shades out the understory forage. Natural succession limits the post-

59 disturbance period when the forage resource is capable of sustaining grazing cattle

60 (Bos taurus L.) to a range of 10 to 15 years in most temperate and boreal coniferous

61 forests (Wikeem et al. 1993).

62 Stand thinning reduces shade and delays canopy closure, and hence may

63 increase forage yields and prolong the silvopasture potential relative to unthinned

64 stands (Moore and Deiter 1992; Peitz et al. 2001). In addition, the quality and quantity of

65 forage produced within forest rangeland may be enhanced by fertilization (Wikeem et al.

66 1993; Sullivan et al. 2012; Lindgren and Sullivan 2014a). From a forest ecosystem

67 perspective, positive biomass responses of understory vegetation have been reported 
68 for stand thinning (Sullivan et al. 2001; Lindgren et al. 2006) and fertilization (Thomas et

69 al. 1999; VanderSchaaf et al. 2002; Lindgren and Sullivan 2013a). Enhanced biomass

70 production of trees and understory vegetation in intensively managed forests may also

71 help to mitigate climate change by providing a steadily increasing carbon sink (Hedwall

72 et al. 2014).

73 However, as discussed by Sullivan et al. (2013), we have yet to document (other

74 than some retrospective studies) long-term decadal changes in stand structure and

75 understory vegetation in intensively managed forests. Thus, to date, there is a very

76 narrow window of time to make extended extrapolations about the development and

77 longevity of changes in forage production for cattle from various forest stand treatments.

78 In addition, the range of pre-commercial thinning (PCT) levels in young forests is quite

79 narrow with a major focus on wood production from an economic perspective. For

80 example, in British Columbia (BC), young lodgepole pine stands have historically been

81 thinned to within a very narrow range of stand densities, typically $1600-2000$ stems/ha,

82 with very few stands < 1000 stems/ha (Sullivan et al. 2013). Similarly, in lodgepole pine

83 forests of the Pacific Northwest of the United States, stocking targets range generally

84 from 1650 to 2250 stems/ha, but with variable densities depending on site index (Koch

85 1996). If creation of "openings" for development and persistence of forage production is

86 desired, then substantially lower densities of PCT are required. Again, as noted by

87 Sullivan et al. (2013), there is a dearth of actual silvicultural treatments designed to

88 grow timber rapidly while simultaneously enhancing other forest values such as

89 silvopasture. 
90 Thus, this study was designed to test the hypothesis that large-scale PCT

91 (particularly heavy thinning to $\leq 1000$ stems/ha), and repeated fertilization, up to 20

92 years after the onset of treatments, would enhance production of understory vegetation,

93 particularly graminoids, forbs, and shrubs as cattle (Bos taurus L.) forage. This paper is

94 one of several periodic publications reporting on long-term responses of tree and stand

95 growth (Lindgren et al. 2007; Lindgren and Sullivan 2013b), mammals (Sullivan et al.

96 2010, 2012), and biodiversity (Sullivan et al. 2009) to these treatments. The current

97 paper reports specifically on forage production for cattle in these experimental stands

98 and how this relates to silvopasture management.

99

100 Study areas and methods

101 Experimental designs and study areas

102 Data from two separate long-term studies with 25- and 20-year datasets were used

103 to test our study hypothesis: (1) PCT (1988-2013) and (2) PCT with fertilization (PCT-

104 FERT) (1993-2013). The PCT study was located at each of three regional replicate

105 areas in south-central BC, Canada: Penticton Creek, Kamloops, and Prince George. In

106 1988, stands were PCT to target densities of 500 (low), 1000 (medium), and 2000

107 stems/ha (high), and unthinned stands had densities $>3000$ stems/ha (unthinned).

108 Treatments were assigned to stands in a randomized complete block design.

109 Unfortunately, overstory trees at the Kamloops and Prince George areas were

110 devastated by the mountain pine beetle (MPB) (Dendroctonus ponderosae Hopk.) in

111 2005. The Penticton area was unaffected, and hence represents an undisturbed

112 replicate block over the 25-year period. The disturbed Kamloops area also continued 
113 after 2005 with measurements of abundance of herb, shrub, and understory tree layers

114 and some surviving overstory tree layers. For the purposes of this paper, data from both

115 Penticton and Kamloops were utilized.

116 The PCT-FERT study had four densities: 250 (very low), 500 (low), 1000 (medium), 117 and 2000 stems/ha (high) with and without a repeated fertilization treatment, and an

118 unthinned-unfertilized stand, replicated initially at each of three areas: Summerland,

119 Kelowna, and Cariboo. Treatments were assigned to stands in a randomized complete

120 block design. Unfortunately, the Cariboo replicate was decimated by MPB in 2005, and

121 hence was not part of this study. The Summerland area was essentially unaffected by

122 MPB and represented an undisturbed complete replicate block over the 20-year period.

123 An outbreak of MPB in 2008, and a ground fire in 2009, resulted in partial disturbance of

124 the Kelowna area, leaving small ( $\leq 0.50 \mathrm{ha}$ ) "islands" of relatively undisturbed forest.

125 These stands provided supplemental data for those datasets collected from the

126 Summerland area where there was little disturbance from MPB. Typical rotation times

127 for intensively managed stands such as these would be $40-50$ years. For the purposes

128 of this paper, data from both Summerland and Kelowna were utilized.

129 Characteristics of the stands at each area in 2013 are listed in Table 1. Further

130 details of study stands are given in Sullivan et al. (2001) and Lindgren et al. (2007). 131

132 PCT and fertilization treatments

133 At the PCT study areas, thinning was conducted in fall 1988 at Penticton and fall

1341989 at Kamloops, and in fall 1993 at each of Summerland, Kelowna, and Cariboo

135 study areas. Slash from the PCT was left on-site, which is currently standard practice in 
136 BC. However, removal of this biomass for energy production may occur in the

137 foreseeable future.

138 At the PCT-FERT study areas, fertilizer treatments were designed as large-scale

139 "optimum nutrition" (Brockley 2005) applications initiated in November 1994 using a

140 blended fertilizer formulated to provide $100 \mathrm{~kg} / \mathrm{ha} \mathrm{N}(100 \mathrm{~N}$ ) (urea), $100 \mathrm{~kg} / \mathrm{ha}$

141 Phosphorus (100 P), $100 \mathrm{~kg} / \mathrm{ha}$ Potassium (100 K), $50 \mathrm{~kg} / \mathrm{ha}$ Sulfur (50 S), $25 \mathrm{~kg} / \mathrm{ha}$

142 Magnesium (25 Mg), and $1.5 \mathrm{~kg} / \mathrm{ha}$ Boron (1.5 B). The objective was to maintain a foliar

$143 \mathrm{~N}$ level of $1.3 \%$, with foliar levels of all other nutrients in proportional balance with foliar

$144 \mathrm{~N}$ concentration. The blended product was applied by helicopter at a rate of $906 \mathrm{~kg} / \mathrm{ha}$

145 to each of the four fertilized stands at the two study areas. Foliar sampling was

146 conducted in the year after fertilization to monitor the nutrient status of the crop trees

147 and develop appropriate multi-nutrient formulations for subsequent fertilizer

148 applications. Treatments were repeated at two-year intervals for a total of five

149 applications: fall 1994, spring 1997, fall 1998, fall 2000, and spring 2003. One hundred,

$150200,150,150$, and 150 for a total of $750 \mathrm{~kg} \mathrm{~N} / \mathrm{ha}$ were applied. Other nutrients

151 (Phosphorus, Potassium, Sulfur, Magnesium, and Boron) were applied with Nitrogen as

152 prescribed from the foliar analyses. Complete descriptions of fertilization treatments are

153 provided in Lindgren et al. (2007).

154

155 Vegetation sampling

156 Vegetation sampling (herbs and shrubs) was designed to measure the effects of

157 PCT, and PCT with repeated fertilization, on individual plant species as well as

158 community-level attributes (Lindgren and Sullivan 2013b). This was accomplished by 
159 transect sampling and provided estimates of abundance by species. A vegetation

160 transect measured $5 \mathrm{~m}$ wide by $25 \mathrm{~m}$ long and was made up of five contiguous $5 \mathrm{~m} \times 5$ -

$161 \mathrm{~m}$ plots. Each plot contained two sizes of nested sub-plots: a $3 \mathrm{~m} \times 3-\mathrm{m}$ sub-plot for

162 sampling shrubs and a $1 \mathrm{~m} \times 1$-m sub-plot for sampling herbs. All plants were

163 subdivided into six height classes: 0-0.25, 0.25-0.5, 0.5-1.0, 1.0-2.0, 2.0-3.0, and > 3.0

$164 \mathrm{~m}$. A given species (an individual plant or group of plants of that species) was described

165 by a visual estimate of percent cover within the appropriate height class. Crown volume 166 index ( $\mathrm{m}^{3} / 0.01 \mathrm{ha}$ ) was then calculated for each plant species as the product of percent 167 cover and its corresponding height (Stickney 1985). In this way, crown volume index 168 provided the volume of a cylindroid and represented the space occupied by the plant in 169 the community. Three permanent vegetation transects were randomly established in 170 each treatment stand. Sampling was conducted during the period of peak productivity

171 (July-August), and was done for the PCT study in 1990, 1993, 1998, 2000-2002, 2008,

172 and 2014 (Penticton) or 2015 (Kamloops). Sampling for the PCT-FERT study was done

173 annually in 1993 to 2003, 2008, and 2013. Plant species were identified in accordance

174 with Hitchcock and Cronquist (1973), MacKinnon et al. (1992), and Parish et al. (1996).

175 Grasses were not identified to species.

177 Estimating biomass from crown volume index

178 Crown volume index approximates the cylindrical space occupied by a plant rather

179 than biomass. Therefore, the critical first step for estimating biomass of herbs and

180 shrubs was to determine the correlation between crown volume index and biomass.

181 Regression equations were then used to estimate biomass from the estimates of crown 
182 volume index for herbs and shrubs in the PCT and PCT-FERT studies. In two separate

183 investigations in the PCT-FERT study areas, we found strong and significant

184 correlations between crown volume index and biomass (Lindgren and Sullivan 2013a).

185 The first study was conducted in 2007 and involved clipping 180 herb plots and

186 correlating the estimated crown volume index with the corresponding oven-dried

187 biomass (Lindgren and Sullivan 2014a). This herb study revealed a strong and

188 significant positive linear relationship for both graminoids $\left(R^{2}=0.95 ; F_{1,17}=154.50 ; P<\right.$

$1890.01)$ and forbs $\left(R^{2}=0.79 ; F_{1,17}=26.12 ; P<0.01\right)$ (Lindgren and Sullivan 2013a). The

190 second study was conducted in 2010 and investigated the correlation between crown

191 volume index and biomass for shrubs using similar methods as described for herbs.

192 This shrub study revealed a strong and significant positive linear relationship for dwarf,

193 low, and tall shrubs (Table 2). Nine dominant shrub species were targeted during this

194 investigation and provided more than $95 \%$ of the total crown volume index of the shrub

195 layer. Inadequate sample size for Linnaea borealis L. and Salix L. spp. precluded any

196 species-specific regression analyses for these species. As a result, data for seven of

197 the nine dominant shrub species were used to develop species-specific regression

198 equations.

199

200 Statistical analysis

201 To analyze the effect of stand density on biomass production, a repeated measures

202 analysis of variance (RM-ANOVA) (IBM Corp. 2015) was conducted to determine the

203 effects of stand treatment (4 levels of PCT: 500, 1000, and 2000, and unthinned) and

204 time on mean biomass of graminoids, forbs, total herbs, total shrubs, and total 
205 understory vegetation. Mean response variables ( $n=4$ stands for each treatment) were

206 measured at 5-, 10, 15-, and 20-year intervals after the thinning treatments.

207 Measurement of response variables at 0 and 2 years post-treatment were also included

208 for graphing purposes, but the limited degree of replication $(n=2)$ at these times

209 precluded their inclusion in the statistical analyses. This same approach was used in the

210 PCT-FERT study with RM-ANOVA comparisons between fertilized and unfertilized

211 stands (averaged across the 4 thinning densities). A one-way ANOVA compared the

212 response variables in these stands prior to the start of treatments in 1988 and 1993. In

213 the PCT-FERT study, stand density had no effect on abundance of understory herbs

214 and shrubs (Lindgren and Sullivan 2013b), and so comparisons were focused on

215 fertilized and unfertilized stands. Pooling data across the 4 thinning treatments was a

216 reasonable approach as no significant density $X$ fertilization interactions were observed

217 for any of the 13 sample years (2-way ANOVA; $\left.F_{3,16} ; P>0.10\right)$. Again, response

218 variables were measured at 5-, 10, 15-, and 20-year intervals after the start of PCT-

219 FERT treatments. Based on a one-way ANOVA, no pre-treatment differences were

220 observed for response variables in the respective comparisons in this investigation.

221 Homogeneity of variances was assessed with Levene's test of equality of error

222 variances. Mauchly's $W$ test statistic was used to test for sphericity (independence of

223 data among repeated measures) (Littel 1989; Kuehl 1994). For data found to be

224 correlated among years, the Huynh-Feldt correction was used to adjust the degrees of

225 freedom of the within-subjects F-ratio (Huynh and Feldt 1976). Duncan's multiple range

226 test (DMRT), with multiple contrasts, was used to compare mean values, whenever a 
227 significant difference was found, based on ANOVA results (Saville 1990). In all

228 analyses, the level of significance was at least $P=0.05$ (Zar 1999).

230 Results

\section{Herb and shrub biomass}

232 The dominant graminoid was pinegrass (Calamagrostis rubescens (Buckl.) and

233 dominant forbs were fireweed (Epilobium angustifolium L.), arctic lupine (Lupinus

234 arcticus S. Wats.), wild strawberry (Fragaria virginiana Duchesne), rosy pussytoes

235 (Antennaria microphylla Rydb.), and white-flowered hawkweed (Hieracium albiflorum

236 Hook.). Mean biomass production ( $\mathrm{kg} / \mathrm{ha}$ ) of graminoids, forbs, and total herbs was not

237 affected by stand density over the 20 post-thinning years of our investigation (Table 3 ;

238 Fig. 1a-c). On average, mean biomass of graminoids ranged from 200 to $326 \mathrm{~kg} / \mathrm{ha}$ and 239 that of forbs from 131 to $165 \mathrm{~kg} / \mathrm{ha}$ over the 20 -year period. Similarly, mean biomass of

240 shrubs and total understory vegetation also followed this pattern (Fig. 2a-b). Mean

241 biomass of shrubs ranged from 107 to $163 \mathrm{~kg} / \mathrm{ha}$, and that of total understory vegetation

242 from 437 to $608 \mathrm{~kg} / \mathrm{ha}$ over the 20 -year period. All response variables showed a

243 significant decline with time after an initial increase, but there were no significant

244 treatment $x$ time interactions (Table 3).

$245 \quad$ Mean biomass was significantly $(P \leq 0.03)$ higher in fertilized than unfertilized

246 stands over the 20-year post-treatment period for graminoids, forbs, total herbs, and

247 total understory vegetation (Table 3; Fig. 3a-c, 4b). These differences in mean biomass

248 of vegetative components ranged from 2.1 to 4.4 times higher in fertilized than

249 unfertilized stands during the fertilization period. The significant time factor showed the 
250 increase in biomass after the start of fertilization and its decline by 15- and 20-years

251 post-treatment. Not surprisingly, there was a significant treatment $\mathrm{x}$ time interaction for

252 the three herbaceous response variables, with a lack of significant fertilizer effect during

253 the early years followed by significantly enhanced biomass during the fertilization

254 period, and a loss of fertilizer effect by 15 years post-treatment (Fig. 3a-c, 5a+b). Mean

255 biomass of shrubs was not affected by fertilization, nor was there a significant time or

256 treatment $x$ time interaction (Table 3; Fig. 4a). Initial measurements of mean biomass in

257 these response variables in 1993, prior to the start of treatments, were similar $(P>$

258 0.05).

259 Mean $(n=2)$ biomass of graminoids among all nine treatment stands from 1993 to

2602013 for the PCT-FERT study clearly showed the positive influence of fertilization during

261 the treatment period (1994 to 2003), and the decline to similar responses among stands

262 in 2008 and 2013 (Fig. 5a). Mean $(n=2)$ biomass of forbs among all nine treatment

263 stands also followed this pattern (Fig. 5b).

264

265 Discussion

266 Herb and shrub biomass

267 Stand density of lodgepole pine did not have an effect on biomass of graminoids,

268 forbs, total herbs, or shrubs, and hence the density part of our hypothesis was not

269 supported. This long-term result (over 20 years) was surprising given that other studies

270 reported significant increases in herb abundance following thinning (Thomas et al. 1999;

271 Thysell and Carey 2001; Lindgren et al. 2006; Cole et al. 2010). However, these

272 published studies were either relatively short-term (up to 5 years post-thinning) or were 
273 conducted in higher productivity coastal forest stands. Mean biomass of these

274 herbaceous components in our thinned stands remained remarkably constant

275 throughout the 20-year period; however, mean biomass in the unthinned stands did

276 seem to decline over time. As suggested by Lindgren and Sullivan (2013a), it is possible

277 that PCT treatments may not have had a significant impact on understory biomass

278 because all of our young thinned stands, including the high-density stands, had

279 relatively open canopy conditions during the early years of these two studies. In

280 addition, all study stands were in a relatively dry environment such that soil moisture

281 may have been limiting in some years.

282 The significant increase in mean biomass of graminoids, forbs, and total herbs to

283 repeated fertilization did support the nutrient addition part of our hypothesis, at least for

284 the herbaceous components. Fireweed, a preferred forage for cattle, was part of the

285 forb component and abundance of this species increased dramatically in fertilized

286 stands (Sullivan et al. 2012). These fertilization-induced increases in biomass of

287 herbaceous components were similar to general increases in abundance of herbs

288 recorded elsewhere, at least where overstory canopy cover was sufficiently open in

289 fertilized stands (Riegel et al. 1991; Kellner and Redbo-Torstensson 1995;

290 VanderSchaaf et al. 2000). A 9-year repeated fertilization experiment with annual

291 additions of nutrients also reported overall increases in abundance of grasses and some

292 herbs in Yukon boreal forest (Nams et al. 1993; Turkington et al. 2001). As for some

293 fertilization effects, the influence of stand density may become significant with time as

294 higher density stands begin to close canopy and shade out herb species, thereby

295 limiting biomass in this understory component. This latter aspect and the end of 
296 repeated fertilization treatments did decrease mean biomass to levels recorded in 297 unfertilized stands at 15 and 20 years post-treatment.

298 Mean biomass of the shrub layer was not affected by stand density or fertilization, 299 and hence the shrub part of our hypothesis was not supported. Reports of responses of 300 shrub abundance to stand thinning have been variable: decreased (Wilson et al. 2009),

301 unaffected (Lindgren et al. 2006; Lindgren and Sullivan 2013a), and enhanced relative

302 to unthinned controls (Thomas et al. 1999). Site-specific conditions (e.g., plant

303 community composition, level of plant competition), thinning intensity (heavy vs. light),

304 and timing of sampling (time since thinning) may have contributed to this variability

305 (Wilson et al. 2009). The enhanced productivity of the herb layer in fertilized stands may

306 have contributed to the lack of shrub response during the initial years of fertilization.

307 However, some shrubs in the fertilized stands appeared to have escaped the presumed

308 herb layer suppression and increased in biomass, particularly the heavily thinned 250

309 stems/ha stands. Fertilization increased the growth rates of all shrubs by about $25-30 \%$

310 over control values over a 9-year period in Yukon boreal forest (Krebs et al. 2001). As

311 with our study, there tended to be a lag time of 5 to 6 years before stable patterns of

312 shrub response appeared (Turkington et al. 1998).

\section{Silvopasture management and carbon storage}

315 The silvopastoral goal of providing forage opportunities for cattle in managed forests

316 seemed to be met in heavily thinned fertilized stands. In terms of actual utility of forage

317 opportunities, relative habitat use by cattle was 2.1 times higher in fertilized than

318 unfertilized stands, and heavily (500 stems/ha) thinned stands had 4.5 and 2.8 times 
319 more use by cattle, respectively, than unthinned stands (Lindgren and Sullivan 2014b).

320 In addition, fertilization may result in sufficient forage production in the understory

321 vegetation of these forest ecosystems to compensate for cattle grazing that reduces the

322 live forage biomass available for native browsing mammals (Lindgren and Sullivan

323 2014b). Forest fertilization also consistently improved forage production for sheep (Ovis

324 aries L.) by an increased abundance of herbs and grasses (Papanastasis et al. 1995).

325 Lindgren and Sullivan (2014a) reported that repeated fertilization increased crude

326 protein content of pinegrass at five years after the most recent application in our stands.

327 Silvopasture, as an agroforestry practice, has considerable importance as a carbon

328 sequestration strategy with the potential for carbon storage in its multiple plant species

329 and wide applicability in managed forests and agricultural lands (Montagnini and Nair

330 2004). Hedwall et al. (2014) noted that fertilization was one of the best methods of forest

331 management to increase net $\mathrm{CO}_{2}$ fixation. Enhanced forest productivity resulting from

332 fertilization can increase carbon storage capacity not only by increasing biomass of

333 trees as reported in several studies (Sathre et al. 2010; Albaugh et al. 2012), but also by

334 increasing cattle forage in the form of graminoids and forbs as reported in our study.

335 Although biomass of understory layers was quite low relative to the tree layers in our

336 forests, the silvopasture component was provided for up to 20 years in heavily thinned

337 stands, prior to canopy closure.

338 Stand thinning to enhance tree growth and forage production for livestock would 339 appear to reduce the capacity for carbon sequestration because of fewer trees on the 340 land base, and potentially reduce the risk of wildland fire. However, as noted by 341 Jimenez et al. (2011) for maritime pine (Pinus pinaster Aiton) in northwestern Spain, 
342 increased growth of residual saplings in heavily thinned stands (more than $90 \%$

343 reduction in density) compensated for much of the carbon storage lost by thinning, at

344 least up to five years post-treatment. If contributions of residues and understory

345 vegetation are taken into account, stand-level carbon storage losses resulting from pre-

346 commercial thinning (PCT) may be further mitigated (Campbell et al. 2009; Jiménez et

347 al. 2011). Similarly, contributions of non-crop trees (ingress) to total stand productivity

348 appeared to be substantial within heavily thinned stands of lodgepole pine 15 years

349 post-thinning (Lindgren and Sullivan 2013b).

350 A caveat was the potential influence of browsing and grazing of herbivores (both wild

351 and domestic) on biomass in these forest ecosystems. According to a comprehensive

352 review by Tanentzap and Coomes (2012), herbivores can reduce terrestrial above- and

353 below-ground carbon stocks but, depending on recovery time of vegetation (i.e., little or

354 no grazing), overall reductions may approach zero. Herbivores in our study areas

355 included cattle, mule deer (Odocoileus hemionus Rafinesque), moose (Alces alces L.),

356 and several species of voles (Microtus spp., Phenacomys intermedius Merriam). We did

357 not measure the potential impact of this herbivory on biomass of understory vegetation

358 in this investigation.

359

360 Conclusions

$361 \quad$ PCT with repeated fertilization enhanced forage biomass for cattle within upland

362 lodgepole pine forests by increasing production and extending the period of forage

363 availability, particularly at stand densities $<1000$ stems/ha. Biomass of graminoids,

364 forbs, and total herbs, but not shrubs, responded positively to fertilization during this 20 - 
365 year investigation. Stand thinning without fertilization had no effect on biomass of 366 understory vegetation during this period.

\section{Acknowledgements}

369 We thank Silviculture Branch, BC Ministry of Forests (MoF), Victoria, BC, the 370 Canada-British Columbia Partnership Agreement on Forest Resource Development

371 (FRDA II), Forest Renewal BC, Forest Innovation Investment; Gorman Bros. Lumber

372 Ltd., Tolko Industries Ltd., Weyerhaeuser Company Limited, and the Alex Fraser

373 Research Forest, University of BC for financial support. Operational treatments were

374 conducted by the Silviculture sections of Penticton and Horsefly Forest Districts (MoF).

375 We also thank the BC Ministry of Agriculture, Agriculture and Agri-Food Canada,

376 Growing Forward: a federal-provincial-territorial initiative, and the Agricultural

377 Greenhouse Gases Program for financial and logistical support. We also thank A.

378 Kozak for guidance with statistical analysis and the many assistants who helped 379 conduct the fieldwork.

381 References

382 Albaugh, T.J., Vance, E.D., Gaudreault, C., Fox, T.R., Allen, H.L., Stape, J.L., and 383 Rubilar, R.A. 2012. Carbon emissions and sequestration from fertilization of pine in 384 the southeastern United States. For Sci. 58: 419-429.

385 Brockley, R. P. 2005. Effects of post-thinning density and repeated fertilization on the 386 growth and development of young lodgepole pine. Can. J. For. Res. 35: 1952-1964. 
387 Campbell, J., Alberti, G., Martin, J., and Law, B.E. 2009. Carbon dynamics of a 388 ponderosa pine plantation following a thinning treatment in the northern Sierra 389 Nevada. For. Ecol. Manage. 257: 453-463.

390 Clason T.R., and Sharrow, S.H. 2000. Silvopastoral practices. In North American $391 \quad$ Agroforestry: An Integrated Science and Practice. Edited by H.E. Garrett, W.J.

392 Rietveld, and R.F. Fisher. American Society of Agronomy, Madison, WI. pp 119-147. 393 Cole, E.C., Hanley, T.A., and Newton, M. 2010. Influence of precommercial thinning on 394 understory vegetation of young-growth Sitka spruce forests in southeastern Alaska. 395 Can. J. For. Res. 40: 619-628.

396 Fox, T.R., Jokela, E.A., and Allen, H.L. 2007. The development of pine plantation 397 silviculture in the southern United States. J. For. 105: 337-347.

398 Hedwall, P-O., Gong, P., Ingerslev, M., and Bergh, J. 2014. Fertilization in northern 399 forests - biological, economic and environmental constraints and possibilities.

$400 \quad$ Scand. J. For. Res. 29: 301-311.

401 Hitchcock, C. L., and Cronquist, A. 1973. Flora of the Pacific Northwest. University of 402 Washington Press, Seattle, Washington. 730 p.

403 Holechek, J.L., Vavra, M., Skovlin, J., and Krueger, W.C. 1982. Cattle diets in the Blue 404 Mountains of Oregon. II. Forests. J. Range. Manage. 35: 239-242.

405 Husak, A.L., and Grado, S.C. 2002. Monetary benefits in a southern silvopasture 406 system. South. J. Appl. For. 26: 159-164.

407 Huynh, H., and Feldt, L.S. 1976. Estimation of the Box correction for degrees of 408 freedom from sample data in the randomized block and split-plot designs. J. Educ. 409 Stat. 1: 69-82. 
410 IBM Corp.Inc. 2015. IBM SPSS Statistics for Windows. Version 23.0 IBM Corp. Armonk, $411 \quad$ NY.

412 Jiménez, E., Vega, J.A., Fernández, C., and Fonturbel, T. 2011. Is pre-commercial 413 thinning compatible with carbon sequestration? A case study in a maritime pine 414 stand in northwestern Spain. Forestry 84: 149-157.

415 Kellner, O., and Redbo-Torstensson, P. 1995. Effects of elevated nitrogen deposition on 416 the field-layer vegetation in coniferous forests. Ecol. Bull. 44: 227-237.

417 Koch, P. 1996. Lodgepole pine in North America. For. Prod. Soc., Madison, WI.

418 Krebs, C.J., Dale, M.R.T., Nams, V.O., Sinclair, A.R.E., and O’Donoghue, M. 2001.

419 Shrubs. In Ecosystem Dynamics of the Boreal Forest. Edited by C.J. Krebs, S.

420 Boutin, and R. Boonstra. Oxford University Press, Oxford, UK, pp. 92-115.

421 Kuehl, R.O. 1994. Repeated measures designs. In Statistical principles of research 422 design and analysis. Duxbury Press, Belmont, CA, pp. 499-528.

423 Lindgren, P.M.F., and Sullivan, T.P. 2013a. Influence of stand thinning and repeated 424 fertilization on plant community abundance and diversity in young lodgepole pine 425 stands: 15-year results. Forest Ecol. Manage. 308: 17-30.

426 Lindgren, P.M.F., and Sullivan, T.P. 2013b. Long-term responses of tree and stand 427 growth of young lodgepole pine to pre-commercial thinning and repeated fertilization. $428 \quad$ Forest Ecol. Manage. 307: 155-164.

429 Lindgren, P.M.F., and Sullivan, T.P. 2014a. Response of forage yield and quality to 430 thinning and fertilization of young forests: implications for silvopasture management. 431 Can. J. For. Res. 44: 281-289. 
432 Lindgren, P.M.F., and Sullivan, T.P. 2014b. Mule deer - cattle interactions in managed

433 coniferous forests during seasonal grazing periods in southern British Columbia,

$434 \quad$ Canada. Wildl. Res. 41: 691-702.

435 Lindgren, P.M.F., Ransome, D.B., Sullivan, D.S., and Sullivan, T.P. 2006. Plant

436 community attributes 12 to 14 years following pre-commercial thinning in a young

437 lodgepole pine forest. Can. J. For. Res. 36: 48-61.

438 Lindgren, P.M.F., Sullivan, T.P., Sullivan, D.S., Brockley R.P., and Winter, R. 2007.

439 Growth response of young lodgepole pine to thinning and repeated fertilization

440 treatments: 10-year results. Forestry 80: 587-611.

441 Littel, R.C. 1989. Statistical analysis of experiments with repeated measures.

$442 \quad$ HortScience 24: 36-40.

443 MacKinnon, A., J. Pojar, and R. Coupé. 1992. Plants of Northern British Columbia.

$444 \quad$ FRDA II B.C. Ministry of Forests and Lone Pine Publishing. Edmonton, Alberta, $445 \quad$ Canada.

446 McDonald, P.M., and Fiddler, G.O. 1993. Feasibility of alternatives to herbicides in 447 young conifer plantations in California. Can. J. For. Res. 23: 2015-2022.

448 Montagnini, F., and P. K. Nair. 2004. Carbon sequestration: An under-exploited 449 environmental benefit of agroforestry systems. Agrofor. Syst. 61: 281-295.

450 Moore, M.M., and Deiter, D.A. 1992. Stand density index as a predictor of forage

451 production in northern Arizona pine forests. J. Range Manage. 45: 267-271.

452 Moore, S.E., and Allen, H.L. 1999. Plantation forestry. In Maintaining Biodiversity in

453 Forest Ecosystems. Edited by M.L. Hunter, Jr. Cambridge University Press, New $454 \quad$ York, NY, pp. 400-433. 
455 Nams, V.O., Folkard, N.F.G., and Smith, J.N.M. 1993. Effects of nitrogen fertilization on 456 several woody and non-woody boreal forest species. Can. J. Bot. 71: 93-97.

457 Papanastasis, V., Koukoura, Z., Alifragis, D., and Makedos, I. 1995. Effects of thinning, 458 fertilisation and sheep grazing on the understory vegetation of Pinus pinaster 459 plantations. For. Ecol. Manage. 77: 181-189.

460 Parish, R., Coupe, R., and Lloyd, D. 1996. Plants of Southern Interior British Columbia. $461 \quad$ Lone Pine Publishing, Vancouver, BC Canada $464 \mathrm{p}$.

462 Peitz, D.G., Shelton, M.G., and Tappe, P.A. 2001. Forage production after thinning a 463 natural loblolly pine-hardwood stand to different basal areas. Wildl. Soc. Bull. 29: $464 \quad 697-705$.

465 Quinton, D.A. 1984. Cattle diets on seeded clearcut areas in central interior British 466 Columbia. J. Range Manage. 37: 349-352.

467 Riegel, G.M., Miller, R.F., and Krueger, W.C. 1991. Understory vegetation response to 468 increasing water and nitrogen levels in a Pinus ponderosa forest in northeast 469 Oregon. Northwest Sci. 65: 10-15.

470 Saville, D.J. 1990. Multiple comparison procedures: the practical solution. Amer. Stat. $471 \quad 44: 174-180$.

472 Sathre, R., Gustavsson, L., and Bergh, J. 2010. Primary energy and greenhouse gas 473 implications of increasing biomass production through forest fertilization. Biomass $474 \quad$ Bioenergy 34: 572-581.

475 Sharrow, S.H. 1999. Silvopastoralism: Competition and facilitation between trees, $476 \quad$ livestock, and improved grass-clover pastures on temperate rainfed lands. In 477 Agroforestry in Sustainable Agricultural Systems. Edited by L.E. Buck, J.P. Lassoie, 478 and E.C.M. Fernandes. CRC Press, Lewis Publishers. Boca Raton, USA. 
479 Stickney, P.F. 1985. Data base for early post-fire succession on the sundance burn, 480 northern Idaho. USDA For. Serv. Intermountain Res. Stat. Gen. Tech. Rep. INT-189.

481 Sullivan, T.P., Sullivan, D.S., and Lindgren, P.M.F. 2001. Stand structure and small 482 mammals in young lodgepole pine forest: 10-year results after thinning. Ecol. $483 \quad$ Applica. 11: 1151-1173.

484 Sullivan, T.P., Sullivan, D.S., and Lindgren, P.M.F. 2012. Influence of repeated 485 fertilization and cattle grazing on forest ecosystems: Abundance and diversity of 486 forest-floor small mammals. Forest Ecol. Manage. 277: 180-195.

487 Sullivan, T.P., Sullivan, D.S., Lindgren, P.M.F., and Ransome, D.B. 2009. Stand 488 structure and the abundance and diversity of plants and small mammals in natural 489 and intensively managed forests. Forest Ecol. Manage. 258S: S127-S141.

490 Sullivan, T.P., Sullivan, D.S., Lindgren, P.M.F., and Ransome, D.B. 2013. Stand 491 structure and small mammals in intensively managed forests: Scale, time, and 492 testing extremes. Forest Ecol. Manage. 310: 1071-1087.

493 Tanentzap, A.J., and Coomes, D.A. 2012. Carbon storage in terrestrial ecosystems: do 494 browsing and grazing herbivores matter? Biol. Rev. 87: 72-94.

495 Thomas, S.C., Halpern, C.B., Falk, D.A., Liguori, D.A., and Austin, K.A. 1999. Plant 496 diversity in managed forests: understorey responses to thinning and fertilization. $497 \quad$ Ecol. Appl. 9: 864-879.

498 Thysell, D.R., and Carey, A.B. 2001. Manipulation of density of Pseudotsuga menziesii 499 canopies: preliminary effects on understory vegetation. Can. J. For. Res. 31:

$500 \quad 1513-1525$.


501 Turkington, R., John, E., Krebs, C.J. et al. 1998. The effects of NPK fertilization for nine 502 years on boreal forest vegetation in northwestern Canada. J. Veg. Science 9: 333503346.

504 Turkington, R., John, E., and Dale, M.R.T. 2001. Plant Dynamics: Herbs and grasses. In 505 Ecosystem Dynamics of the Boreal Forest. Edited by C.J. Krebs, S. Boutin, and R. 506 Boonstra, Oxford University Press, Oxford, UK, pp. 70-91.

507 VanderSchaaf, C.L., Moore, J.A., and Kingery, J.L. 2002. The effect of multinutrient 508 fertilization on understory vegetation annual production. West. J. Appl. For. 17: 147$509 \quad 153$.

510 Wikeem, B.M., Newman, R.F., and van Ryswyk, A.L. 1993. Forage response to N, P, 511 and S fertilization on clearcut lodgepole pine sites. J. Range Manage. 46: 262-270.

512 Willms, W., Mclean, A., Tucker, R., and Ritcey, R. 1980. Deer and cattle diets on 513 summer range in British Columbia. J. range Manage. 33: 55-59.

514 Wilson, D.S., Anderson, P.D., and Puettmann, K.J. 2009. Evaluating the consistency of 515 understorey vegetation response to forest thinning through synthetic analysis of 516 operational-scale experiments. Forestry 82: 583-596.

517 Zar, J.H. 1999. Biostatistical Analysis. Prentice-Hall, Inc., Englewood Cliffs, N. J. 663 $518 \quad$ pp. 
519 Table 1. Experimental design and characteristics of lodgepole pine stands for the PCT and PCT + FERT studies in 2013.

\begin{tabular}{|c|c|c|c|c|c|c|c|c|}
\hline \multirow[b]{2}{*}{$\begin{array}{l}\text { Study area } \\
\text { and stand }\end{array}$} & \multicolumn{3}{|c|}{ Density (stems/ha) } & \multicolumn{3}{|c|}{$\begin{array}{l}\text { Attributes of dominant tree layer } \\
\qquad(\text { mean } \pm \mathrm{SE})\end{array}$} & \multirow[b]{2}{*}{ Area (ha) } & \multirow[b]{2}{*}{ Canopy closure $(\%)$} \\
\hline & Crop trees ${ }^{1}$ & $\begin{array}{c}\text { Non-crop }{ }^{2} \\
\text { trees }\end{array}$ & Total conifers & $\mathrm{DBH}(\mathrm{cm})$ & Height (m) & Age (yr) & & \\
\hline
\end{tabular}

\section{PCT}

\section{Penticton}

\begin{tabular}{|c|c|c|c|c|c|c|c|c|}
\hline Low & 550 & 2680 & 3230 & $21.8 \pm 0.3$ & $13.9 \pm 0.1$ & 42 & 20.0 & 87.4 \\
\hline Medium & 1190 & 2915 & 4105 & $18.7 \pm 0.2$ & $15.4 \pm 0.1$ & 42 & 20.0 & 89.8 \\
\hline High & 1670 & 3170 & 4840 & $16.9 \pm 0.2$ & $14.7 \pm 0.1$ & 42 & 20.0 & 92.3 \\
\hline Unthinned & 5070 & 3050 & 8120 & $10.1 \pm 0.3$ & $11.5 \pm 0.2$ & 42 & $100+$ & 88.9 \\
\hline \multicolumn{9}{|l|}{ Kamloops $^{3}$} \\
\hline Low & 85 & 2525 & 2610 & $18.3 \pm 4.4$ & $14.1 \pm 1.8$ & 47 & 22.0 & - \\
\hline Medium & 260 & 840 & 1100 & $15.8 \pm 2.4$ & $15.1 \pm 1.8$ & 47 & 15.0 & - \\
\hline High & 1070 & 490 & 1560 & $13.6 \pm 1.8$ & $12.9 \pm 0.9$ & 47 & 19.0 & - \\
\hline Unthinned & 3840 & 155 & 3995 & $13.1 \pm 0.4$ & $14.0 \pm 0.5$ & 47 & $100+$ & - \\
\hline
\end{tabular}

\section{PCT and Fertilization}

Summerland

$\begin{array}{lccccccrr}\text { Very low } & 264 & 4845 & 5109 & 19.4 \pm 0.3 & 10.2 \pm 0.1 & 33 & 11.3 & 70.4 \\ \text { Very low } & 226 \mathrm{~F} & 1365 & 1591 & 19.3 \pm 0.2 & 9.2 \pm 0.1 & 33 & 11.3 & 73.3 \\ \text { Low } & 496 & 4290 & 4786 & 16.6 \pm 0.2 & 9.6 \pm 0.1 & 33 & 7.6 & 76.5 \\ \text { Low } & 501 \mathrm{~F} & 2060 & 2561 & 18.3 \pm 0.2 & 9.2 \pm 0.1 & 33 & 7.6 & 86.1\end{array}$




\begin{tabular}{|c|c|c|c|c|c|c|c|c|}
\hline Medium & 923 & 2637 & 3560 & $15.5 \pm 0.1$ & $9.3 \pm 0.1$ & 33 & 4.5 & 85.9 \\
\hline Medium & $911 \mathrm{~F}$ & 770 & 1681 & $18.6 \pm 0.3$ & $10.4 \pm 0.1$ & 33 & 4.5 & 86.6 \\
\hline High & 1691 & 1613 & 3304 & $14.3 \pm 0.2$ & $9.4 \pm 0.1$ & 33 & 4.4 & 87.4 \\
\hline High & $1458 \mathrm{~F}$ & 854 & 2312 & $15.5 \pm 0.2$ & $9.3 \pm 0.1$ & 33 & 4.4 & 91.0 \\
\hline Unthinned & 8095 & 1125 & 9220 & $9.1 \pm 0.2$ & $7.8 \pm 0.1$ & 33 & 5.0 & 91.9 \\
\hline \multicolumn{9}{|l|}{ Kelowna } \\
\hline Very low & 281 & 2325 & 2606 & $19.9 \pm 0.4$ & $11.4 \pm 0.2$ & 33 & 10.0 & 69.2 \\
\hline Very low & $242 \mathrm{~F}$ & 4967 & 5209 & $20.4 \pm 0.7$ & $11.8 \pm 0.4$ & 33 & 10.0 & 83.5 \\
\hline Low & 576 & 3050 & 3626 & $16.7 \pm 0.4$ & $10.8 \pm 0.2$ & 33 & 11.0 & 78.9 \\
\hline Low & $569 F$ & 1367 & 1936 & $18.9 \pm 0.6$ & $12.2 \pm 0.4$ & 33 & 11.0 & 93.2 \\
\hline Medium & 982 & 3025 & 4007 & $17.4 \pm 0.6$ & $12.5 \pm 0.3$ & 33 & 9.5 & 90.4 \\
\hline Medium & $841 \mathrm{~F}$ & 3025 & 3866 & $17.7 \pm 0.5$ & $12.6 \pm 0.2$ & 33 & 9.5 & 93.7 \\
\hline High & 1722 & 4000 & 5722 & $13.7 \pm 0.4$ & $11.6 \pm 0.2$ & 33 & 11.9 & 89.1 \\
\hline High & $1548 \mathrm{~F}$ & 540 & 2088 & $15.0 \pm 0.4$ & $12.2 \pm 0.2$ & 33 & 11.9 & 92.6 \\
\hline Unthinned & 3510 & 1625 & 5135 & $13.5 \pm 0.5$ & $12.2 \pm 0.2$ & 33 & 12.6 & 94.2 \\
\hline
\end{tabular}

$520{ }^{1}$ Crop trees of lodgepole pine in 2013; crop trees were those trees retained during the PCT treatment.

$521{ }^{2}$ Non-crop trees arise from ingress over time.

$522 \quad 32008$.

$523 \quad F=$ fertilized stand 
Table 2. Results of the stature-specific regression analyses developed from the 9 dominant shrub species sampled. Coefficients describe the simple linear relationship between crown volume index ( $\left.\mathrm{m}^{3} / 0.01 \mathrm{ha}\right)$ and dry biomass ( $\left.\mathrm{g} / 0.01 \mathrm{ha}\right)$.

\begin{tabular}{|lccc}
\hline Regression & \multicolumn{3}{c}{ Shrub stature (height range) } \\
attributes & Dwarf $(<0.25 \mathrm{~m})$ & Low $(0.25$ to $2.0 \mathrm{~m})$ & Tall $(>2.0 \mathrm{~m})$ \\
\hline Sample size $(n)$ & 97 & 100 & 38 \\
Slope $(m)$ & 103.82 & 67.35 & 44.62 \\
Constant $(b)$ & 25.97 & 9.05 & 26.48 \\
$R^{2}$ & 0.46 & 0.77 & 0.90 \\
$P$-value & $<0.01$ & $<0.01$ & $<0.01$ \\
\hline
\end{tabular}

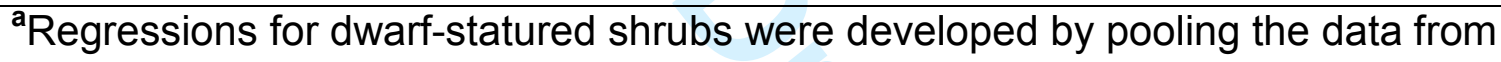
Arctostaphylos uva-ursi (L.) Sprengel, Pachistima myrsinites Nutt., Vaccinium scoparium Leib. ex Coville, and Linnaea borealis L.; low-statured regressions were developed by pooling data from Ribes lacustre (Pers.) Poir., and Spiraea betulifolia Pall; tall-statured regressions were developed by pooling data from Alnus sinuata (Regel) Rydb and Salix L. spp. 
Table 3. Results of RM-ANOVA for biomass responses of graminoids, forbs, total herbs, shrubs, and total understory vegetation in response to lodgepole pine stand density (stems/ha): low (500), medium (1000), high (2000), and unthinned, and PCT stands fertilized and unfertilized at 5, 10, 15, and 20 years post-treatment. F-values identified by * were calculated using an $\mathrm{H}-\mathrm{F}$ correction factor, which decreased the stated degrees of freedom due to correlation among repeated measures. Significant values in bold text.

\begin{tabular}{|c|c|c|c|c|c|c|c|c|c|c|c|c|}
\hline \multirow{3}{*}{ Plant group } & \multicolumn{6}{|c|}{ PCT only } & \multicolumn{6}{|c|}{ PCT + FERT } \\
\hline & \multicolumn{2}{|c|}{$\underline{\text { Treatment }}$} & \multicolumn{2}{|c|}{$\underline{\text { Time }}$} & \multicolumn{2}{|c|}{$\underline{\text { Treatment } x \text { time }}$} & \multicolumn{2}{|c|}{$\underline{\text { Treatment }}$} & \multicolumn{2}{|c|}{$\underline{\text { Time }}$} & \multicolumn{2}{|c|}{ Treatment $x$ time } \\
\hline & $F_{3,12}$ & $P$ & $F_{3,36}$ & $P$ & $F_{9,36}$ & $P$ & $F_{1,14}$ & $P$ & $F_{3,42}$ & $P$ & $F_{3,42}$ & $P$ \\
\hline Graminoids & 0.13 & 0.94 & $5.01^{*}$ & $<0.01$ & $1.11^{*}$ & 0.38 & 7.46 & 0.02 & $16.48^{*}$ & $<0.01$ & $5.72^{*}$ & $<0.01$ \\
\hline Forbs & 0.43 & 0.74 & 3.66 & 0.02 & 0.85 & 0.58 & 6.88 & 0.02 & $5.77^{*}$ & 0.01 & $6.16^{*}$ & $<0.01$ \\
\hline Total herbs & 0.13 & 0.94 & $6.06^{*}$ & $<0.01$ & $1.28^{*}$ & 0.29 & 8.09 & 0.01 & $10.48^{*}$ & $<0.01$ & $6.77^{*}$ & $<0.01$ \\
\hline Total shrubs & 1.57 & 0.25 & 3.46 & 0.03 & 1.10 & 0.39 & 0.04 & 0.85 & $1.19^{*}$ & 0.32 & $0.63^{*}$ & 0.53 \\
\hline Total herbs+shrubs & 0.34 & 0.80 & 6.03 & $<0.01$ & 1.38 & 0.24 & 6.13 & 0.03 & $9.96^{*}$ & $<0.01$ & $6.82^{*}$ & $<0.01$ \\
\hline
\end{tabular}




\section{List of Figures}

Figure 1. Mean ( $n=4$ replicate stands; $n=2$ for year 0$) \pm$ SE biomass production (kg/ha) of (a) graminoids, (b) forbs, and (c) total herbs at 0, 2, 5, 10, 15, and 20 years post-treatment (pre-commercial thinning) among four densities (stems/ha) of lodgepole pine: low (500), medium (1000), high (2000), and unthinned.

Figure 2. Mean ( $n=4$ replicate stands; $n=2$ for year 0$) \pm$ SE biomass production ( $\mathrm{kg} / \mathrm{ha}$ ) of (a) shrubs, and (b) total herbs and shrubs (understory) at $0,2,5,10$, 15 , and 20 years post-treatment (pre-commercial thinning) among four densities (stems/ha) of lodgepole pine: low (500), medium (1000), high (2000), and unthinned.

Figure 3. Mean ( $n=8$ replicate stands) \pm SE biomass production $(\mathrm{kg} / \mathrm{ha})$ of $(\mathrm{a})$ graminoids, (b) forbs, and (c) total herbs at $0,5,10,15$, and 20 years posttreatment in unfertilized and fertilized lodgepole pine stands. F = fertilization.

Figure 4. Mean ( $n=8$ replicate stands) \pm SE biomass production ( $\mathrm{kg} / \mathrm{ha}$ ) of (a) shrubs, and (b) total herbs and shrubs (understory) at $0,5,10,15$, and 20 years posttreatment in unfertilized and fertilized lodgepole pine stands. F = fertilization.

Figure 5. Mean ( $n=2$ replicate stands) biomass production $(\mathrm{kg} / \mathrm{ha})$ of $(\mathrm{a})$ graminoids and (b) forbs annually from 1993 to 2003 and at 5-year intervals from 2003 to 2013 for four densities $(250,500,1000,2000$ stems/ha) of unfertilized and fertilized lodgepole pine stands, and an unthinned pine stand. F = fertilization. 
Figure 1.
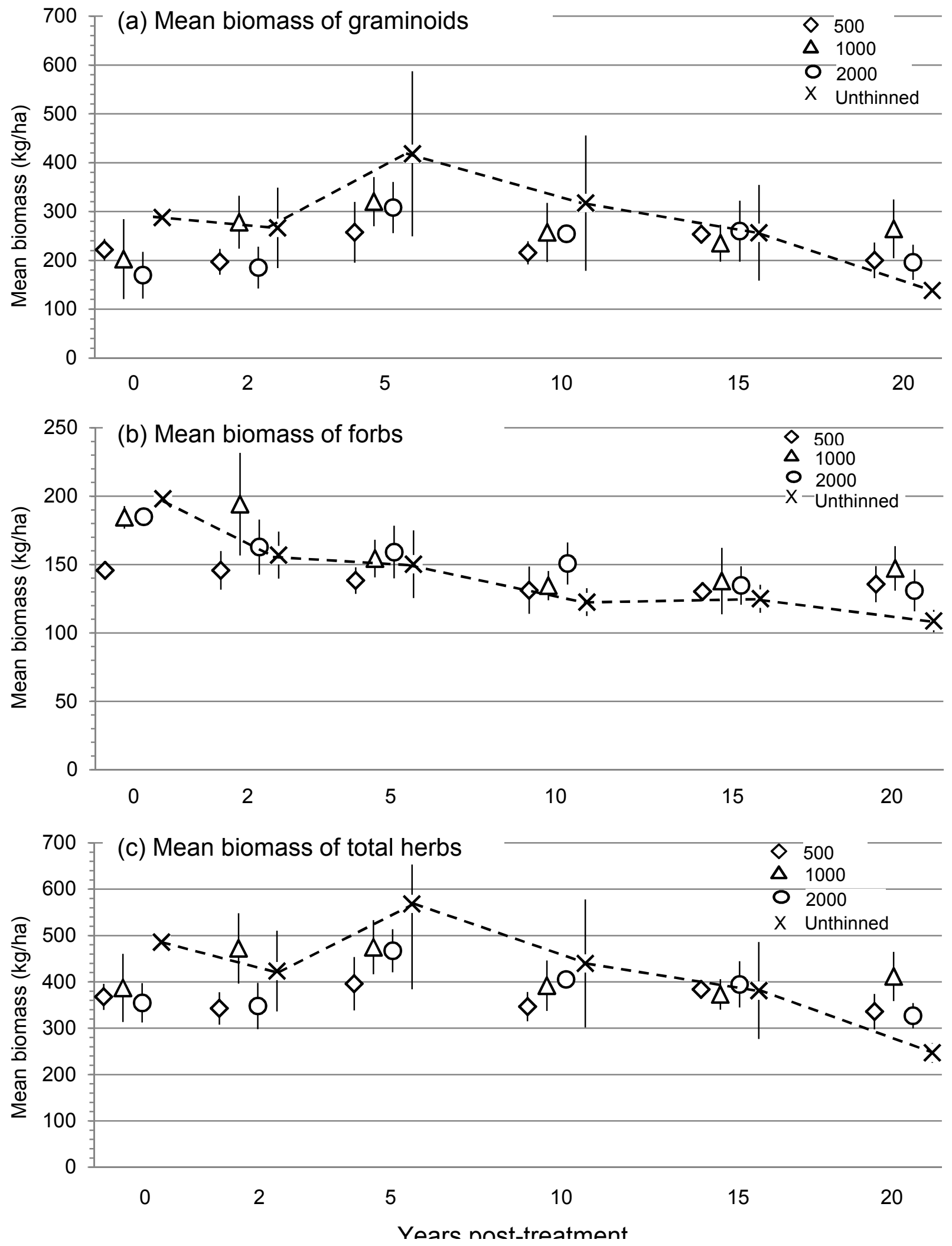
Figure 2.
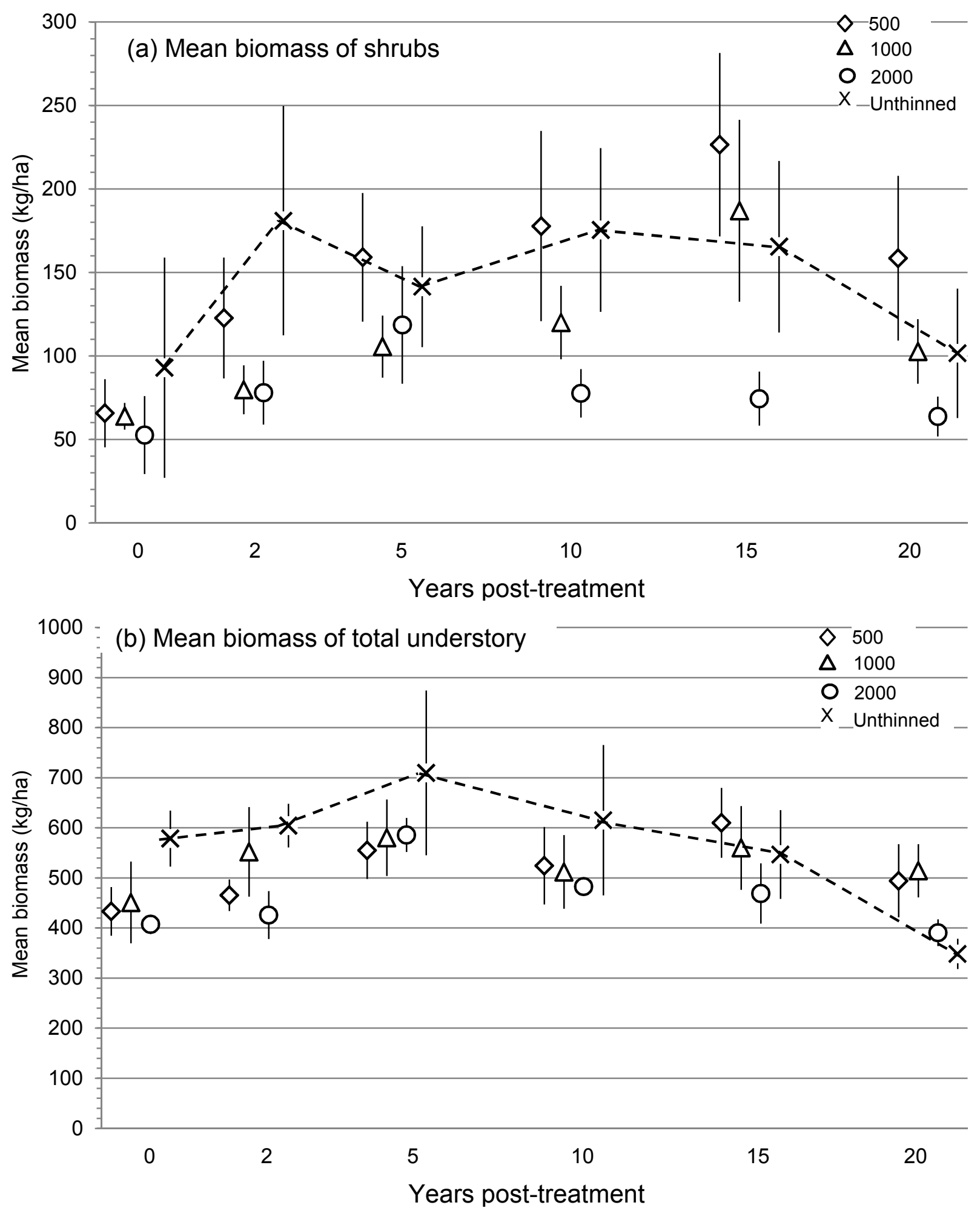
Figure 3.
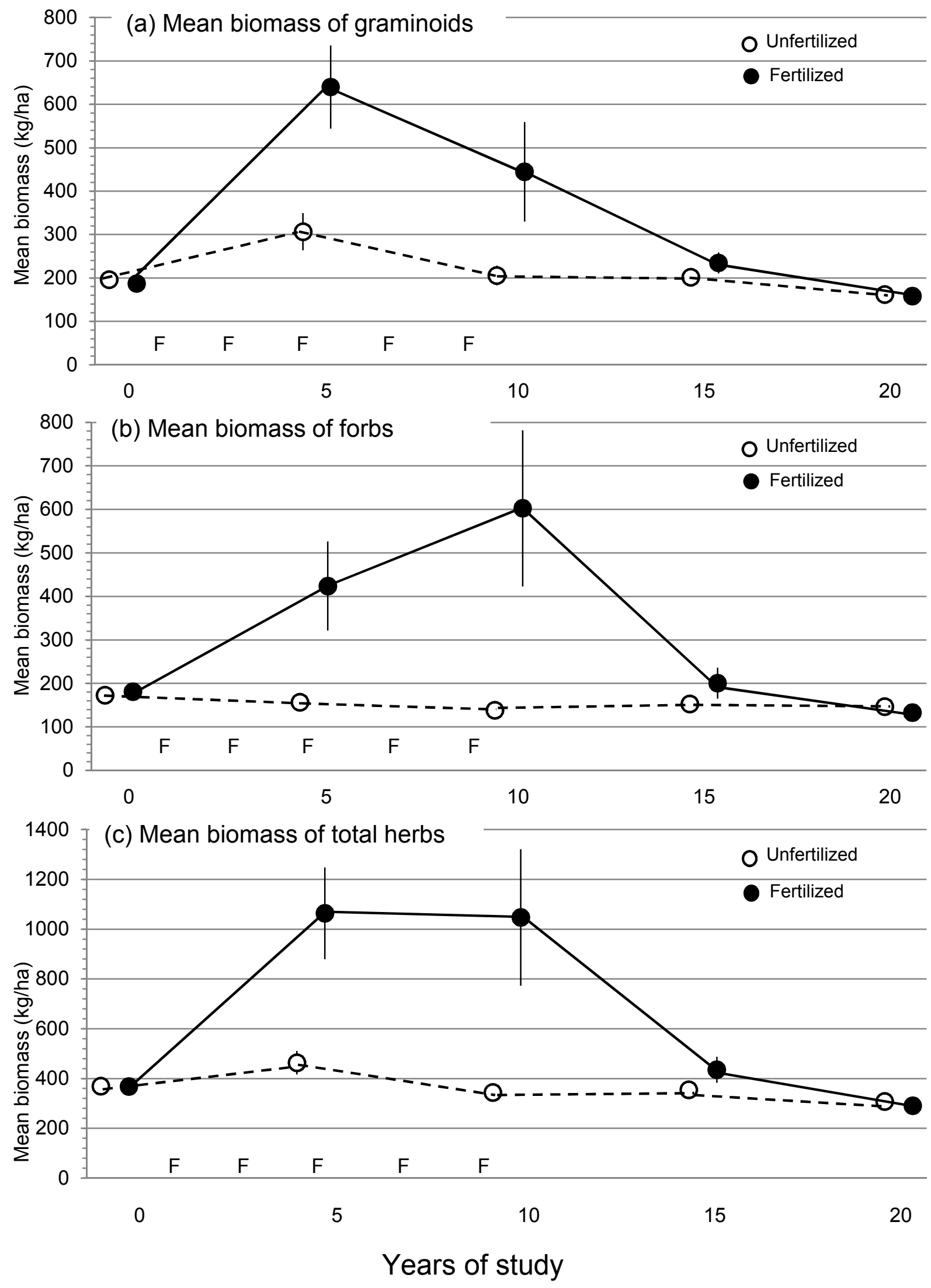
Figure 4.
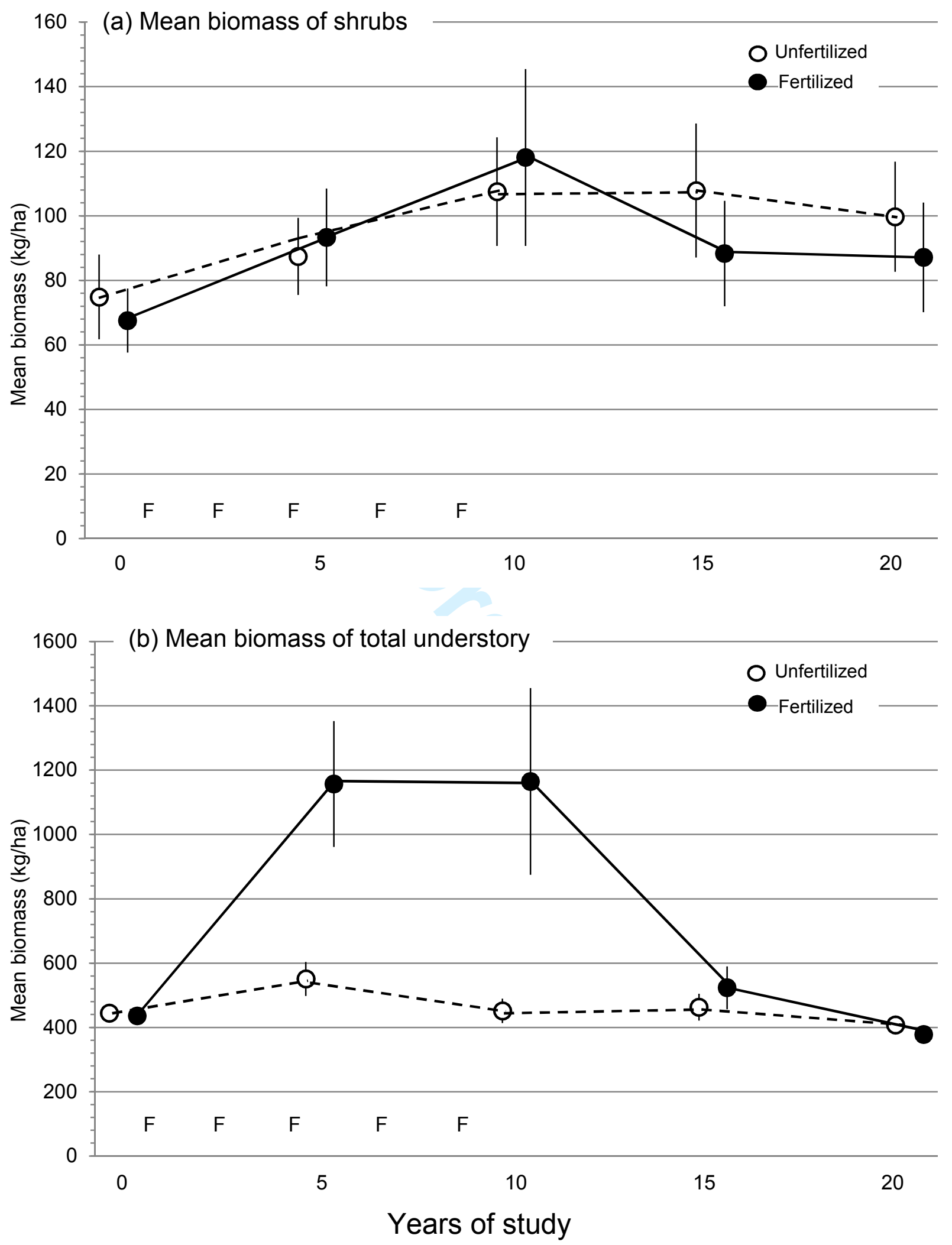
Figure 5.

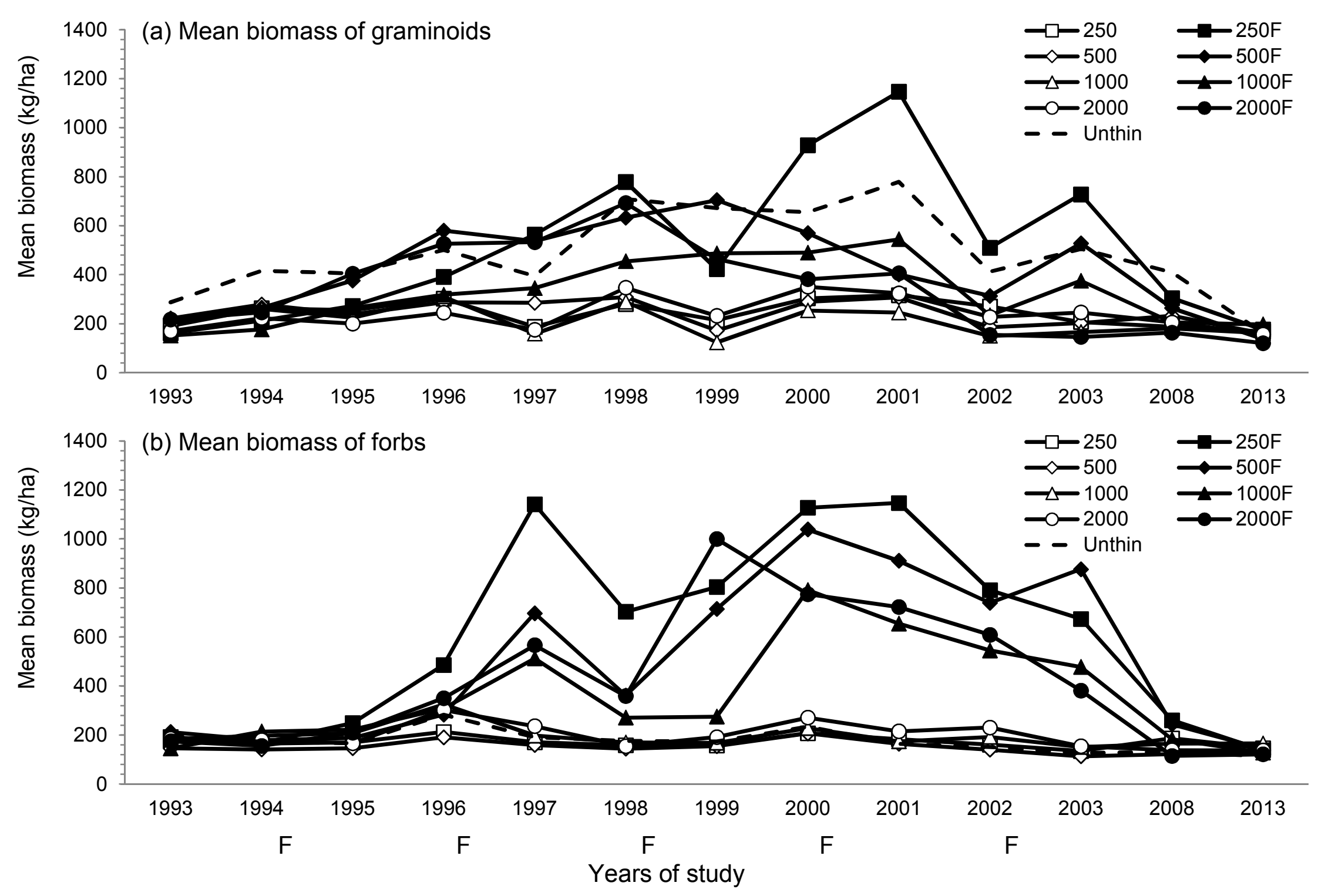

